\title{
Pulmonary Hypertension and Pulmonary Disorders in Cystic Fibrosis
}

\section{Paula Maria Eidt Rovedder ${ }^{1 *}$, Francini Porcher Andrade ${ }^{2}$ and Paulo de Tarso Roth Dalcin ${ }^{3}$}

${ }^{1}$ Professor, Adjunta do Curso de Fisioterapia e do Programa de Pós-graduação em Ciências Pneumológicas; Universidade Federal do Rio Grande do Sul (UFRGS), Hospital de Clínicas de Porto Alegre (HCPA), Porto Alegre, Rio Grande do Sul, Brazil

${ }^{2}$ Fisioterapeuta, Pesquisadora HCPA, Faculdade de Fisioterapia, Centro Universitário Metodista do Sul - IPA, Porto Alegre, Rio Grande do Sul, Brazil

${ }^{3}$ Professor, Titular da Faculdade de Medicina e do Programa de Pós-graduação em Ciências Pneumológicas, UFRGS, HCPA, Porto Alegre, Rio Grande do Sul, Brazil

Keywords: Cystic fibrosis; Pulmonary hypertension; Exercise

\section{Introduction}

Cystic fibrosis (CF) is a progressive, hereditary, autosomal recessive disorder that is more common among Caucasians [1-3]. It was first described by Dorothy H. Andersen in 1938 as "cystic fibrosis of the pancreas" to classify exocrine pancreatic destruction. In 1953, Di Sant'Agnese demonstrated that these patients lose excessive salt in their sweat, leading to adoption of electrolytic methods for diagnosis of the disease [1]

Cystic fibrosis is associated with pancreatic failure and progressive lung disease, due to a defect that compromises the CFTR gene, resulting in an increase of the viscosity of glandular secretions and reduced mucociliary clearance, which deregulates the lungs' innate defenses, causing persistent respiratory infections, which result in progressive decline in pulmonary function and premature death [1,3-6]

Early diagnosis of the disease contributes to interventions designed to prevent or improve pulmonary exacerbation, but the progressive nature of $\mathrm{CF}$ and the side effects of treatment can have negative impacts on all aspects of life $[7,8]$.

\section{Pathophysiology of the Pulmonary Component of Cystic Fibrosis}

Lung disease in CF is caused by a lack of, or a defect in, the CFTR gene, which causes an ionic cell disorder. There is a reduction in secretion of chloride via the defective channel, associated with exaggerated resorption of sodium and, secondary to this, of water into the cell interior, causing an ionic imbalance in the cell which results in dehydration of the mucus, causing increased viscosity and reduced mucociliary activity, provoking the emergence of secondary infections and inflammation $[1,9]$.

Some studies have suggested that changes to the salt concentration in bronchial mucosa cause inhibition of the activity of respiratory tract defensins (antibacterial peptides), reducing resistance to bacterial pathogens $[1,10]$

Bacterial colonization secondary to retention of secretions (primarily by Pseudomonas and Staphylococcus) makes metaplasia of the bronchial epithelium more likely, with mucoid impaction and disorganization of the cilia structure. Mucosal plugs then appear in the bronchi and bronchioles, with acute and chronic lymphocytic infiltration [11].

The presence of thick secretions that become infected leads to obstruction of the small airways and triggers a chronic inflammatory process. The inflammation, which is already present in the anatomically normal lungs of newborn infants, leads to formation of bronchiectasis and pulmonary damage $[12,13]$. A study by Sly et al. demonstrated that elevated activity of neutrophils in the lungs of 3-month-old children with cystic fibrosis was responsible for the presence of bronchiectasis, suggesting that treatments to inhibit the activity of these cells could delay the emergence of this pulmonary abnormality [13].

\section{Diagnosis of Cystic Fibrosis}

Diagnosis of CF is based on the presence of one or more phenotypical characteristics, on a positive family history or on a positive neonatal screening test, combined with evidence of abnormalities in the CFTR gene. The phenotypical characteristics most commonly associated with $\mathrm{CF}$ are related to the pulmonary disease (recurrent infections by pathogens that are typical of CF; chronic coughing and sputum production; abnormal chest x-ray findings; airway obstructions; nasal polyps, chronic sinusitis and nail clubbing), gastrointestinal abnormalities (meconium ileus; steatorrhea; rectal prolapse; pancreatic failure with consequent development of diabetes mellitus; recurrent pancreatitis), nutritional disorders (failure to thrive/inadequate development; protein-energy malnutrition; hypoproteinemia and edema), salt loss syndromes (acute salt depletion and chronic metabolic alkalosis), male infertility (obstructive azoospermia) and reduced female fertility $[1,3,11]$.

In clinical practice, the gold standard for diagnosis of $\mathrm{CF}$ is the sweat test. The test consists of quantitative determination of chlorides in sweat, obtained by iontophoresis with pilocarpine $[1,14]$. The minimum quantity of sweat is $100 \mathrm{mg}$ and the result is positive when the chloride concentration in the sample is greater than $60 \mathrm{mEq} / \mathrm{l}$. Two positive tests confirm a diagnosis of CF. Normal levels can be as high as $40 \mathrm{mEq} / \mathrm{l}$; values from 40 to $60 \mathrm{mEq} / \mathrm{l}$ are considered inconclusive and indicate that the test should be repeated $[1,11,14]$.

Another method of diagnosis is by identification of two known CF mutations. Analysis of these mutations offers high specificity, but low sensitivity, because more than 1300 mutations have so far been identified and, in clinical practice, available tests are restricted to a small number of the most frequent mutations $[11,15,16]$.

The lifespans of patients with CF can be extended by using the most recent antibiotics, lung transplantation and the possibility of successful gene therapy [17].

\section{Respiratory Manifestations of Cystic Fibrosis}

The most common respiratory manifestation is chronic coughing, which may occur during the first weeks of life. The majority of the patients exhibit productive coughing with abundant and thick pulmonary secretions that are difficult to eliminate [18]

*Corresponding author: Paula Maria Eidt Rovedder, Curso de Fisioterapia a Universidade Federal do Rio Grande do Sul, Porto Alegre, Rio Grande do Sul, Brazil Tel: +55 51 9841-8290; E-mail: larove@ @hotmail.com

Received September 01, 2015; Accepted October 05, 2015; Published October 12, 2015

Citation: Rovedder PME, Andrade FP, Dalcin PDTR (2015) Pulmonary Hypertension and Pulmonary Disorders in Cystic Fibrosis. Cardiovasc Pharm Open Access 4: 158. doi:10.4172/2329-6607.1000158

Copyright: (C) 2015 Rovedder PME, et al. This is an open-access article distributed under the terms of the Creative Commons Attribution License, which permits unrestricted use, distribution, and reproduction in any medium, provided the original author and source are credited. 
The most important functional disorders in CF are obstruction of airflow, air entrapment and inadequate ventilation. As these manifestations progress, they are predominantly characterized by obstructive ventilatory disorders. It is only in the final phases of the disease that a restrictive component caused by pulmonary fibrosis emerges [11].

In order to classify the functional severity of CF lung disease, it is necessary to conduct a spirometry test and, depending on the forced expiratory volume in 1 second, patients' cases will be defined as mild if percentage forced expiratory volume in 1 second $\left(\% \mathrm{FEV}_{1}\right)>80$; moderate if $\% \mathrm{FEV}_{1}$ is 60 to 80 ; severe when $\% \mathrm{FEV}_{1}$ is $40-60$ and very severe when $\% \mathrm{FEV}_{1}$ is $<40$ [1].

As the lung disease progresses, a large percentage of patients will develop pulmonary hypertension $(\mathrm{PH})$ and hypertrophy of the right ventricle (cor pulmonale). Among the factors that cause $\mathrm{PH}$ in these patients, are destruction of large portions of the pulmonary capillary bed and remodeling of the walls of the small arteries, with increased pulmonary vascular resistance. Cor pulmonale manifests in advanced stages of the lung disease and its appearance is associated with severe hypoxemia or an inadequate ventilation-perfusion ratio $[4,19,20]$.

In addition, some studies have found a relationship between $\mathrm{FEV}_{1}$ and the presence of HP, and this can be considered as a predictor of pulmonary artery systolic pressure (PASP) [21,22].

\section{Pulmonary Hypertension in Cystic Fibrosis}

Pulmonary hypertension is characterized by a chronic increase in pulmonary artery pressure, overloading the right ventricle with hypertrophy and dilation of the right ventricle, which can progress to heart failure [23].

Development of $\mathrm{PH}$ among people with $\mathrm{CF}$ varies according to age and the severity of the disease; chronic alveolar hypoxia, in hypoventilated areas, leads to reflexive vasoconstriction in the pulmonary arterial bed, significantly contributing to increased PASP [20,23-25]. With the prolonged hypoxic state, the pulmonary circulation undergoes structural changes known as remodeling, i.e., there is hypertrophy and hyperplasia of the tunica media of the arterial vessels, and muscularization of the pulmonary arterioles. This mechanism triggers increased peripheral vascular resistance and consequent $\mathrm{PH}$. Chronic inflammation of the airways and air entrapment, both of which are present in $\mathrm{CF}$, can also lead to pulmonary vascular remodeling and cause $\mathrm{PH}[25]$.

Recent studies have investigated right ventricle function in patients with CF. Studies have demonstrated that the transmembrane conductance of the CFTR gene intervenes in regulation of contraction of cardiomyocytes by means of maintenance of a resting potential of the membrane, preventing an intracellular calcium overload, which could lead to myocardial hypercontraction. As such, the CFTR gene in the myocardium protects against necrotic myocardial injury induced by ischemia. Therefore, in patients with CF regulation of the activity of the myocardium, which should be reduced by the CFTR gene, does not take place, explaining the right ventricle dysfunction and development of disproportional elevation of pulmonary artery blood pressure in some individuals $[25,26]$.

Clinical evidence of $\mathrm{PH}$ in patients with $\mathrm{CF}$ is an indicator of worse prognosis and is associated with progression of the lung disease [20]. Therefore, periodic tests should be performed to control the $\mathrm{PH}$ progression in these patients $[4,11]$.

\section{Diagnosis of Pulmonary Hypertension}

Pulmonary Hypertension is characterized by pulmonary artery pressure that is disproportionately high for the level of pulmonary blood flow. The variables that control pulmonary artery pressure are cardiac output and pulmonary vascular resistance [4,27].

Mean pulmonary artery pressure (MPAP) greater than $25 \mathrm{~mm}$ $\mathrm{Hg}$ at rest or $30 \mathrm{~mm} \mathrm{Hg}$ during exercise is sufficient to diagnose $\mathrm{PH}$. Pressure is measured by cardiac catheterization, which is the gold standard for diagnosis of $\mathrm{PH}$, or noninvasively using echocardiogram with Doppler [4,24,27,28].

Doppler echocardiogram is the most sensitive noninvasive method for investigation of $\mathrm{PH}$. This method can be used to estimate PASP by determination of the tricuspid regurgitation velocity during right ventricular systole (in the absence of pulmonary stenosis, systolic pressure of the right ventricle, the primary estimate, is virtually identical to PASP) $[4,24]$. The doppler echocardiogram is method used to screen patients with PAH [29]. Studies demonstrate that PASP estimated by echocardiogram is positively correlated with MPAP measured invasively, with values equal to or greater than $35 \mathrm{~mm} \mathrm{Hg}$. Therefore, the Doppler echocardiography should be adopted as an important measure in monitoring the PSAP in patients with $\mathrm{CF}$, given that $\mathrm{HP}$ is a poor prognostic factor and difficult to diagnose in the FC $[4,22]$.

\section{Classification of Pulmonary Hypertension}

Pulmonary Hypertension may have silent onset as a consequence of systemic diseases, heart diseases, diseases of the pulmonary parenchyma or abnormalities of the pulmonary vasculature $[24,25]$.

The $5^{\text {th }}$ World Symposium on PH was held in 2013 in France and resulted in a revised classification. The classification identifies five groups of diseases, as follows: pulmonary arterial hypertension, $\mathrm{PH}$ due to left heart disease, $\mathrm{PH}$ due to lung diseases and/or hypoxemia, chronic thromboembolic $\mathrm{PH}, \mathrm{PH}$ with unclear multifactorial mechanisms [30].

In $\mathrm{CF}, \mathrm{PH}$ is considered an essentially hypoxic mechanism, with complementary participation of structural changes to the pulmonary parenchyma caused by progression of the underlying disease [31]. Additionally, obstruction of airflow and wide variations in intrathoracic pressure can increase venous return to the right side of the heart, resulting in increased pulmonary artery flow and exacerbation of the already elevated overload on the right ventricle [25].

With the objective of characterizing the impact of $\mathrm{PH}$ on daily activities, conducting follow-up, intervening therapeutically and providing orientation with regards to prognosis, the New York Heart Association (NYHA) functional classification of $\mathrm{PH}$, as modified by the World Health Organization [WHO), has been adopted, as follows [28]:

Class I: Without limitation of physical activity. Ordinary physical activity does not cause undue dyspnea or fatigue, chest pain, or near syncope.

Class II: Slight limitation of physical activity. These patients are comfortable at rest, but ordinary physical activity causes undue dyspnea or fatigue, chest pain, or near syncope.

Class III: Marked limitation of physical activity. These patients are comfortable at rest, but less than ordinary activity causes undue dyspnea or fatigue, chest pain, or near syncope.

Class IV: Inability to carry out any physical activity without symptoms. These patients manifest signs of right-heart failure. Dyspnea and/or fatigue may even be present at rest and discomfort is increased by any physical activity. 
Notwithstanding, some authors consider the material subjective because of the varying symptoms exhibited by these patients $[28,32]$.

\section{Drug Treatments for Pulmonary Hypertension}

Drug treatments for $\mathrm{PH}$ are intended to avoid vascular remodeling and aid in vasodilation and three main classes of pharmaceuticals are used for this: Group 1 comprises endothelin receptor antagonists; Group 2 drugs are phosphodiesterase type 5 inhibitors (iF5), such as sildenafil, which prolong the vasodilator effects of nitric oxide; and group 3 medications are prostacyclins, which induce vasodilation of the pulmonary vasculature. Two new classes of drugs have demonstrated satisfactory results for treatment of $\mathrm{PH}$ : soluble guanylate cyclase stimulators, which provoke relaxation of the vascular smooth muscle, and prostacyclin analogs, which induce arterial vasodilation. The primary focus of studies of these treatments has been on improving the capacity to exercise, by analyzing increases in the distance covered in the 6 minute walk test (6MWT), which is a very widely used and inexpensive instrument for assessing progression of functional status in $\mathrm{PH}$ [33]. The medications for $\mathrm{PH}$ do not serve to treat patients with FC [34].

The monotherapy treatment with sildenafil can reduce pulmonary vascular resistance and improve exercise tolerance in patients with $\mathrm{PH}[35,36]$. The study of Montgomery used for two weeks sildenafil in patients with $\mathrm{CF}$ and $\mathrm{PH}$ and found significant improvement in pulmonary hemodynamics and functional capacity by increasing the distance of the 6MWT [35].

Taylor-Cousar et al.[36] evaluated the pharmacokinetics, tolerability, and safety of sildenafil in subjects with CF. The conclusions that Sildenafil administration was safe in subjects with CF and decreased sputum elastase activity.

Galiè et al.[37], conducted a clinical trial comparing the combined use of sildenafil and riociguat at HP. The study did not show favorable results, and the individuals who used the combination of the two drugs showed hypotension and death, moreover, there was no improvement in exercise tolerance and pulmonary hemodynamics.

\section{Assessment of Functional Status}

The assessment of functional status in patients with pulmonary involvement is important to assess the severity of the disease, exercise tolerance and the benefits obtained with the treatment because the role of drug treatment at HP is to preserve the functional status of patients. The tests used to assess exercise capacity in these patients are the $6 \mathrm{MWT}$ and cardiopulmonary exercise test (CPET) $[33,38]$.

The 6MWT is a submaximal test of effort that is controlled, is easy to administer and is rapid, and in which the result of the test is the total distance covered. The results are predictive of survival in $\mathrm{PH}$ and are negatively correlated with NYHA functional class. The Borg scale is administered during the 6MWT - a subjective assessment of perceived dyspnea and fatigue in the patient's lower extremities [21,38,39].

Some authors have demonstrated that people with CF-related $\mathrm{PH}$ who walk less than 332 meters during the $6 \mathrm{MWT}$ exhibit a higher mortality rate, demonstrating that presence of $\mathrm{PH}$ characterizes greater severity of CF and implies lower tolerance of exercise [40].

In contrast, the CPET is a maximal effort test, conducted on a treadmill or cycloergometer, making it possible to measure ventilation and gaseous exchange during exercise, providing values for maximum oxygen uptake $\left(\mathrm{VO}_{2 \max }\right)$. Patients with $\mathrm{PH}$ exhibit low $\mathrm{VO}_{2 \max }$ and low work rate [38].
Rovedder et al. [21], assessed the functional capacity of patients with CF through the 6MWT and found no significant difference in the distance traveled by individuals with and without HP. However, lung function, represented by FEV1 and the forced vital capacity (FVC), showed a significant difference between patients with HP, demonstrating that the presence of $\mathrm{PH}$ in $\mathrm{CF}$ is related to severity of lung disease. In the same study, it was shown that poor clinical scores are correlated with larger diameters of the right ventricle, with the longest acceleration of systolic flow lung-artery right ventricle and with higher values of the PSAP.

\section{Exercise in Patients with Cystic Fibrosis and in Pulmonary Hypertension}

Patients with CF frequently exhibit progressive limitations to physical exercise and reductions in activities of daily living. The primary causes of exercise intolerance are associated with a reduction in ventilatory capacity and reserve, loss of peripheral skeletal muscle mass and reduction in cardiovascular function. The limiting symptoms exhibited by patients with CF during exercise include fatigue, dyspnea, bronchospasm, ventilatory limitations and cardiac dysfunction [41].

In patients with chronic lung disease, physical limitations can also be associated with right ventricle dysfunction. Meerkerk et al. demonstrated that presence of $\mathrm{PH}$ in patients with $\mathrm{CF}$ made a significant contribution to worse clinical and functional scores, such as a shorter distance covered in the 6MWT [4].

In $\mathrm{CF}$, as in other lung diseases, desaturation is accentuated during exercise. Episodes of hypoxemia and hypercapnia can occur during periods of physiological stress, primarily during exercise. It has been suggested that hypoxemia and moderate hypercapnia affect these patients during exercise because of limitation to expiratory flow and insufficient ventilation [4]. Study that investigated prevalence of HP in adult CF patients demonstrated an inverse correlation between the PSAP and the oxygen saturation $\left(\mathrm{SpO}_{2}\right)$ at rest and after the 6MWT. The $\mathrm{SpO}_{2}$ at rest was the best predictor of HP in these individuals [21]. Adult patients with advanced lung disease and $\mathrm{PH}$ may exhibit significant increases in MPAP in response to exercise, which is a common response that can compromise the functional capacity of these patients. Notwithstanding, the previous criterion for avoiding exercise (increase in MPAP to $>30 \mathrm{~mm} \mathrm{Hg}$ ) was excluded from the most recent definition of $\mathrm{PH}$, and the parameters level of activity and patient age are now preferred [25].

\section{Conclusion}

$\mathrm{PAH}$ in patients with cystic fibrosis is associated with age, disease severity, increased risk of mortality and reduced exercise tolerance. The evaluation of the functional status of the patient is important to encourage the holding of regular exercise under professional supervision. Furthermore, there is a need for improved monitoring of drug therapy HP set to prevent the progression of clinical symptoms, improve the functional capacity and quality of life for patients.

\section{References}

1. Bush A, Alton EWFW, Davies JC, Griensebach U, Jaffe A (2006) Progress in Respiratory Research. In: Chris T. Bolliger (eds) Cystic Fibrosis in the 21st Century. (Vol 34), Karger Publishers, Switzerland.

2. Jadin SA, Wu GS, Zhang Z, Shoff SM, Tippets BM, et al. (2011) Growth and pulmonary outcomes during the first 2 y of life of breastfed and formula-fed infants diagnosed with cystic fibrosis through the Wisconsin Routine New-born Screening Program. Am J Clin Nutr 93: 1038-1047.

3. Alicandro G, Frova L, Di Fraia G, Colombo C (2015) Cystic fibrosis mortality trend in Italy from 1970 to 2011. J Cyst Fibros 14: 267-274 
Citation: Rovedder PME, Andrade FP, Dalcin PDTR (2015) Pulmonary Hypertension and Pulmonary Disorders in Cystic Fibrosis. Cardiovasc Pharm Open Access 4: 158. doi:10.4172/2329-6607.1000158

4. Belle-van Meerkerk G, Cramer MJ, Kwakkel-van Erp JM, Nugroho MA, Tahri S, et al. (2013) Pulmonary hypertension is a mild comorbidity in end-stage cystic fibrosis patients. J Heart Lung Transplant 32: 609-614.

5. McKone EF, Emerson SS, Edwards KL, Aitken ML (2003) Effect of genotype on phenotype and mortality in cystic fibrosis: A retrospective cohort study. Lancet 361: 1671-1676.

6. Wainwright CE, Elborn JS, Ramsey BW, Marigowda G, Huang X, et al. (2015) Lumacaftor-Ivacaftor in Patients with Cystic Fibrosis Homozygous for Phe508del CFTR. N Engl J Med 373: 220-231.

7. Beydon N, Robinson PD (2013) Early intervention for new-borns screened for cystic fibrosis. Am J Respir Crit Care Med 188: 409-410.

8. Tluczek A, Becker T, Laxova A, Grieve A, Racine Gilles CN, et al. (2011) Relationships among health-related quality of life, pulmonary health, and newborn screening for cystic fibrosis. Chest 140: 170-177.

9. Ratjen F, Doring G (2003) Cystic fibrosis. Lancet 361: 681-689.

10. Dinwiddie R (2000) Pathogenesis of lung disease in cystic fibrosis. Respiration 67: 3-8.

11. Yankaskas JR, Marshall BC, Sufian B, Simon RH, Rodman D (2004) Cystic fibrosis adult care: Consensus conference report. Chest 125: 1S-39S.

12. Orenstein DM (2000) The respiratory system. Cystic Fibrosis. Lippincott Williams and Wilkins, Philadelphia.

13. Sly PD, Gangell CL, Chen L, Ware RS, Ranganathan S, et al. (2013) Risk factors for bronchiectasis in children with cystic fibrosis. N Engl J Med 368: 1963-1970.

14. Koch C, Høiby N (2000) Diagnosis and treatment of cystic fibrosis. Respiration 67: 239-247.

15. Rowe SM, Miller S, Sorscher EJ (2005) Cystic fibrosis. N Engl J Med 352: 1992-2001.

16. Drumm ML, Konstan MW, Schluchter MD, Handler A, Pace R, et al. (2005) Genetic modifiers of lung disease in cystic fibrosis. N Engl J Med 353: 1443 1453.

17. Koelling TM, Dec GW, Ginns LC, Semigran MJ (2003) Left ventricular diastolic function in patients with advanced cystic fibrosis. Chest 123: 1488-1494.

18. Lyczak JB, Cannon CL, Pier GB (2002) Lung infections associated with cystic fibrosis. Clin Microbiol Rev 15: 194-222.

19. Hodson ME (2000) Treatment of cystic fibrosis in the adult. Respiration 67 595-607.

20. Tonelli AR, Fernandez-Bussy S, Lodhi S, Akindipe OA, Carrie RD, et al. (2010) Prevalence of pulmonary hypertension in end-stage cystic fibrosis and correlation with survival. J Heart Lung Transplant 29: 865-872.

21. Rovedder PM, Ziegler B, Pasin LR, Rampon G, Pinotti AF, et al. (2007) Doppler echocardiogram, oxygen saturation and submaximum capacity of exercise in patients with cystic fibrosis. J Cyst Fibros 6: 277-283.

22. Bright-Thomas RJ, Ray SG, Webb AK (2012) Pulmonary artery pressure in cystic fibrosis adults: characteristics, clinical correlates and long-term followup. J Cyst Fibros 11: 532-538.

23. Hayes D Jr, Tobias JD, Mansour HM, Kirkby S, McCoy KS, et al. (2014) Pulmonary hypertension in cystic fibrosis with advanced lung disease. Am J Respir Crit Care Med 190: 898-905.

24. Chemla D, Castelain V, Herv ÃP, Lecarpentier Y, Brimioulle S (2002) Haemodynamic evaluation of pulmonary hypertension. Eur Respir J 20: 13141331.

25. Tonelli AR (2013) Pulmonary hypertension survival effects and treatment options in cystic fibrosis. Curr Opin Pulm Med 19: 652-661.

26. Sellers ZM, De Arcangelis V, Xiang Y, Best PM (2010) Cardiomyocytes with disrupted CFTR function require CaMKII and $\mathrm{Ca}(2+)$-activated $\mathrm{Cl}(-)$ channel activity to maintain contraction rate. J Physiol 588: 2417-2429.

27. Badesch DB, Champion HC, Sanchez MA, Hoeper MM, Loyd JE, et al. (2009) Diagnosis and assessment of pulmonary arterial hypertension. J Am Coll Cardiol 54: S55-66.

28. Rubin LJ (2004) Diagnosis and management of pulmonary arterial hypertension ACCP evidence-based clinical practice guidelines. Chest. 126: 7S-10S.
29. Janda S, Shahidi N, Gin K, Swiston J (2011) Diagnostic accuracy of echocardiography for pulmonary hypertension: A systematic review and metaanalysis. Heart 97: 612-622.

30. Simonneau G, Gatzoulis MA, Adatia I, Celermajer D, Denton C, et al. (2013) Updated clinical classification of pulmonary hypertension. J Am Coll Cardio 62: D34-41.

31. Orenstein DM (2000) The respiratory system. Cystic Fibrosis. Lippincot Williams and Wilkins, Philadelphia.

32. Taichman DB, McGoon MD, Harhay MO, Archer-Chicko C, Sager JS, et al. (2009) Wide Variation in Clinicians' Assessment of New York Heart Association/ World Health Organization Functional Class in Patients With Pulmonary Arteria Hypertension. Mayo Clin Proc 84: 586-592.

33. Panagiotou M, Peacock AJ, Johnson MK (2015) Respiratory and limb muscle dysfunction in pulmonary arterial hypertension: A role for exercise training? Pulm Circ 5: 424-434.

34. 34. Kerem E, Konstan MW, De Boeck K, Accurso FJ, Sermet-Gaudelus I, et al. (2014) Ataluren for the treatment of nonsense-mutation cystic fibrosis: A randomised, double-blind, placebo-controlled phase 3 trial. Lancet Respir Med 2: 539-547.

35. Montgomery GS, Sagel SD, Taylor AL, Abman SH (2006) Effects of sildenafi on pulmonary hypertension and exercise tolerance in severe cystic fibrosisrelated lung disease. Pediatr Pulmonol 41: 383-385.

36. Taylor-Cousar JL, Wiley C, Felton LA, St Clair C, Jones M, et al. (2015) Pharmacokinetics and tolerability of oral sildenafil in adults with cystic fibrosis lung disease. J Cyst Fibros 14: 228-236.

37. Galiè N, Müller K, Scalise AV, Grünig E (2015) PATENT PLUS: A blinded, randomised and extension study of riociguat plus sildenafil in pulmonary arterial hypertension. Eur Respir J 45: 1314-1322.

38. Galiè N, Torbicki A, Barst R, Dartevelle P, Haworth S, et al. (2004) Guidelines on diagnosis and treatment of pulmonary arterial hypertension. The Task Force on Diagnosis and Treatment of Pulmonary Arterial Hypertension of the European Society of Cardiology. Eur Heart J 25: 2243-2278.

39. ATS Committee on Proficiency Standards for Clinical Pulmonary Function Laboratories (2002) ATS statement: Guidelines for the six-minute walk test. Am J Respir Crit Care Med 166: 111-117.

40. Blau H, Mussaffi-Georgy H, Fink G, Kaye C, Szeinberg A, et al. (2002) Effects of an intensive 4-week summer camp on cystic fibrosis: pulmonary function, exercise tolerance, and nutrition. Chest 121: 1117-1122.

41. Orenstein DM (2000) Exercise. Cystic fibrosis. Lippincott Williams and Wilkins Philadelphia. 